\title{
Prismotherapy in opthalmology
}

\section{Oftalmolojide prizmalarla tedavi uygulamaları}

\author{
Hüseyin BAYRAMLAR ${ }^{1}$, Remzi KARADAĞ ${ }^{1}$, Özgür ÇAKICI ${ }^{1}$, Mahnur BAYRAMLAR ${ }^{2}$
}

\section{SUMMARY}

Thanks to their optical peculiarities, prisms could be used to correct diplopia by realigning the visual axis. Though they can not generally achieve a cure, the prisms often correct the symptoms such as diplopia and abnormal head posture which can be very disturbing for patients. Recently, it has been shown that oblique peripheral prisms improved responses of people with homonymous hemianopia to blind spot hazards when driving. Prisms may also be used to expand visual field in the patients with tubular vision due to retinitis pigmentosa etc. In this paper, we reviewed the prismotherapy, its indications and contraindications.

Key word: Fresnel prism, prism, prismotherapy, optic treatment

\section{ÖZET}

Prizmalar optik özellikleri sayesinde görme eksenlerini düzelterek çift görmeyi ortadan kaldırırlar. Genelde tam bir şifa sağlayamazlarsa da, çift görme ve anormal baş pozisyonu gibi, hastaları çok rahatsız eden semptomların giderilmesini sıklıkla sağlarlar. Son zamanlarda oblik periferik prizmaların homonim hemianopili bireylerde, araba sürme gibi aktivitelerde kör alanların bir miktar görünür hâle gelmesine yardımcı oldukları gösterilmiştir. Prizmalar ayrıca retinitis pigmentoza gibi hastalıklar nedeniyle görme alanı daralmış olan bireylerde görme alanını bir miktar genişletmek için kullanılabilir. Bu makalede prizma tedavisi, endikasyon ve kontrendikasyonları derlenmeye çalışılmıştır.

Anahtar kelimeler: Fresnel prizma, prizma, prizmoterapi, optik tedavi

\section{Giriş}

Prizma gelen ışığı tabanına doğru yönlendirerek kıran bir optik yapıdır. İki türlü prizmatik cam şekli bulunmaktadır:

1. Klasik cam prizma: Esasen plastik materyalden yapılmıştır. Yan kesiti basit üçgen şeklinde olan tek bir prizmadan oluşur. Kaliteli görüntüyü bozmadan, bir göz önünde 8 , iki gözde 16 prizma diyoptriye (PD) kadar gözlüğe monte edilebilir. Diyoptrisi arttıkça kalınlık ve ağırlığı artar, daha fazla yansıma ve aberasyonlara sebep olur ve estetik olmaktan uzaklaşır ${ }^{1,2}$.

2. Fresnel Prizma: Plastik bir membrandan oluşur. Küçük ardışık prizmaların etkisinin birleşmesi sayesinde kalın tek bir prizmayla aynı kırma gücüne sahiptir. Cam prizmadan daha ince ve hafif, dola- yısıyla daha estetiktir. Gözlük şablonuna göre kesilip ıslatılarak gözlüğe yapıştırılır. Zamanla sararma yapar. Distorsiyon etkisi minimaldir. Diyoptrisi arttıkça görme keskinliğini azaltır. Bu nedenle ancak 30 PD.'ye kadar mevcuttur. Otuz beş-40 PD. tolere edilemez. Genelde bir gözde 15-20 PD.'ye kadar kullanılır ${ }^{1-3}$.

Fresnel prizmayı tolere edemeyenler için mandal mekanizmasıyla (clip-on) gözlük camına tutturulan prizmalar, günümüzde artık üretilmemektedir .

Prizma Adaptasyon Testi (PAT): Muayenede tesbit ettiğimiz prizma diyoptrisi bazı durumlarda günlük yaşamdaki durumu tam olarak yansıtmaz. Bulunandan daha az veya fazla bir prizma gerekli olabilir. Bu nedenle prizma kullanımından önce prizma adaptasyon testi kullanılması birçok durumda yararlı ve gerekli-

Received: 05.06 .2015

Accepted: 21.06.2015

${ }^{1}$ İstanbul Medeniyet Üniversitesi Tıp Fakültesi, Göz Hastalıkları Anabilim Dalı

${ }^{2}$ Düzce Üniversitesi Tıp Fakültesi

Yazışma adresi: Dr. Hüseyin Bayramlar, İstanbul Medeniyet Üniversitesi Tıp Fakültesi, Göz Hastalıkları Anabilim Dalı, İstanbul

e-mail: hbayramlar@yahoo.com 
dir. Veronneau-Troutman, bu testi aşağıdaki şekilde uygulamaktadır:

1. Gerekli tashihin (gerekirse bifokal) üzerine prizma örtme testinde bulunan vertikal ve horizontal kayma açısını düzeltecek prizma takılır. Kural olarak, oblik prizmalar ve Fresnel prizma kullanılmaz.

2. Uzak ve yakına bakıştaki kayma açısı farklıysa, büyük açı nötralize edilir. Uzak ve yakına bakışta diplopi devam ederse, prizma diyoptrisi tek görme elde edilinceye kadar azaltılır.

3. Bulunan total prizma iki göze eşit olarak dağıtılır. $15 \mathrm{dk}$. arayla alternan örtme testi yapılarak, prizma derecesi gerekirse değiştirilir. Bir buçuk saat sonunda açı sabitlenmiş olur, yakın ve uzak için kaydedilir. Prizmalı iken duyusal testler yapılır. Test sonlandırılır².

Prizma adaptasyon testinde eğer prizma gözlüğe monte edilemeyecek kadar geniş bir açı bulunursa, çoğunlukla prizma tedavisi uygulanmaz, cerrahi gerekir $^{2}$.

\section{Prizmatik cam tashihinin kullanım amaçları:}

- Görme eksenlerini kaydırmak ve diplopiyi düzeltmek (motor etki).

- Binoküler görme elde etmek (duyusal etki).

- Ameliyat sonrası bakiye kaymayı veya müteakip aşırı düzeltmeyi gidermek.

\section{Prizmatik cam tashihinin kullanım alanları}

Prizmatik camlar özellikle ameliyat endikasyonu olan, ancak genel durumu ameliyata uygun olmayan hastalarda, ayıca tiroid orbitopati gibi şaşılık açısının zamanla değişebildiği durumlarda cerrahiyi bekleme dönemi boyunca semptomları gidermek için kullanılır. Bu makalede prizma kullanım alanları başlıca 4 grupta ele alınacaktır:

- A. Komitan şaşılıklar

- B. İnomitan şaşılıklar

- C. Nistagmus

- D. Diğer endikasyonlar.

\section{A. Komitan şaşılıklar}

\section{A1. Heteroforyada prizma tedavisi}

Toplumun büyük çoğunluğunda bir miktar heteroforya vardır. Heteroforyalar genelde uzun yıllar latent kalır ve semptoma yol açmazlarsa da astenopik şikayetlere yol açması durumunda tedavisi gerekebilir. Ancak, bu astenopik yakınmaların nedeninin heteroforyaya bağlı olduğuna emin olmak gerekir. Bunun için de öncelikle diğer olası nedenler ekarte edilmelidir. Örneğin, eğer bir gözlük değişiminden sonra semptomatik forya ortaya çıkmışsa, neden olasılıkla camın desantralizasyonu veya kötü yerleştirilmesinin ortaya çıkardığı prizmatik etkidir. Diğer nedenler arasında baskın gözün değişmesi, daha önce düzeltilmemiş eski refraksiyonun düzeltilmiş olması, akomodasyon-konverjans gereksinimindeki ani artış, gözlükten kontakt lense geçme veya hastaya refraktif cerrahi yapılmış olması gibi nedenler belirtilebilir. Miyopide kalın kenarlı uzağa odaklanmış gözlük, yakına bakışta tabanı içerde prizma etkisi yapar. Diverjans uyarılır. Akomodasyon gereksinimi artar ve ekzoforik miyopta yakın çalışmada astenopi yakınmaları ortaya çıkar. Refraktif cerrahi veya kontakt lens ile bu durum ortadan kalkar. Ezoforik hipermetropide ise tersine akomodasyon gereksiniminin azalmasıyla durum kompanse edilir ${ }^{2}$. von Noorden, heteroforyada prizmaların füzyon amplitüdünü azaltarak bağımlılık yaptığını belirtmekte olup, prizma kullanımını daha çok semptomatik ezoforyalı yaşlı bireylerde uygun bulmaktadır.

Semptomatik foryanın nedenini bulmak için, öykü, görsel gereksinim, refraksiyon, tashih şekli, akomodasyonun yakın noktası ve motilite dikkatle değerlendirilmelidir. Füzyon amplitüdü düşük ve iki gözle birlikte görme keskinliği iyi olmayan dekompanse heteroforyalar ortoptik tedavi gerektirir.

Hastada hem vertikal hem de horizontal forya mevcut olabilir. Böyle durumlarda normal vertikal füzyon amplitüdü horizontalden daha kısıtlı olduğu için, klasik öğretiye göre önce vertikal forya düzeltilmelidir. Bu, hastanın semptomlarını giderip horizontal 
düzeltme gereksinimini ortadan kaldırabilir². Bazı yazarlar ezoforyanın tam düzeltilmesini savunmaktadırlar ${ }^{5}$. Bazıları da aktif füzyonal diverjansı korumak ve prizma diyoptrisini arttırma gereğini önlemek için 1/3-2/3 oranında az düzeltmeyi önerirler ${ }^{6}$.

Eğer heteroforyalı hastada PAT'da 25-30 PD gibi geniş bir açı prizma tesbit edilirse, prizma tedavisi değil, cerrahi tedavi düşünülmelidir. Bazı otörler, heteroforya tedavisi için ters prizma önermektedir. Bu amaçla ezoforya (E) tedavisi için 1-2 PD tabanı içerde, ekzoforya $(X)$ içinse 3-4 PD tabanı dışarıda prizma reçete etmektedirler ${ }^{7}$.

A2. Konverjans-Diverjans egzersizi için prizma kullanımı:

Füzyon amplitüdü düşük, astenopik yakınmalı, normal retinal korrespondansa sahip hastalarda füzyon amplitüdünü çalıştırmak için prizma kullanılabilir. Bazen konverjans yetmezliği, küçük bir ezoforya veya ekzoforya ile birlikte olabilir; bu durumdaki hastalar konverjans egzersizinden yarar görebilir. Konverjans egzersizi prizmalarla da yapılabilir. Bazen bir hasta füzyonal amplitüdü çok az, ama asemptomatik olabilirken, bazen de asemptomatik bir hasta bu egzersizlerden sonra semptomatik hâle gelebilir. Bunun dışında, geniş ekzoforyası olan presbiyopik bir hasta, gözlük yakın kısmına yerleştirilen tabanı içerde prizmalardan yarar görebilir².

\section{A3. Heterotropyada prizma tedavisi}

- Çocukta kazanılmış paralitik olmayan ezotropya (ET): Bu tür hastalar prizma tedavisine iyi bir adaydır. Kazanılmış paralitik olmayan ET'li çocuklarda, sensoryel durumu normale getirmede prizma tedavisi kazanılmış ekzotropyaya (XT) göre daha etkisizdir. Oyun ve okul çağındaki çocuklarda, sonradan ortaya çıkan şaşılıklar kesinlikle kafa içi kitle olasıllı̆ını saymak için manyetik rezonans görüntülemeyi içeren bir nörolojik inceleme yapılmalıdır?.

- Rezidüel ET: Seyrek değildir. Önce hipermetropik tashih denenmelidir. Cerrahi öncesi akomodatif olmayan durum, cerrahi sonrası akomodatif komponent gösterebilir. Hipermetropik tashih yarar göstermezse, prizma tedavisi yararlı olabilir. von Noorden bu hasta grubunda prizma kullanılmasını önermemektedir ${ }^{4}$.

- Müteakip (Consecutive) ET: Prizma tedavisi için kusursuz endikasyondur. Özellikle 5 yaşın altında oldukça yararlıdır. Bu hastalarda yaş ne kadar küçükse, o kadar hızlı supresyon, ambliyopi ve anormal retinal korrespondans (ARK) yerleşebilir. Eğer uzak ve yakında ET mevcutsa ve birkaç hafta gözlem ve kısmi kapatma sonrasında da ET azalmıyorsa, emetrop veya miyop çocukta prizma uygundur ${ }^{10,11}$. Hipermetropide önce hipermetropik tashih denenmelidir ${ }^{10,11}$.

- Intermitant XT: 5 yaşından önce ameliyat pek önerilmez. Çünkü bu erken yaş döneminde oluşabilecek bir izleyen ET, binokülariteyi $\mathrm{XT}^{\prime}$ den daha çok ve çabuk bozar ${ }^{12}$. Intermitan ekzotropyada cerrahi dışı tedavide öncelik miyopik aşırı düzeltmedir ${ }^{13}$. Miyopik aşırı düzeltme yapılamazsa, prizma tedavisi cerrahi gereksinimini ortadan kaldırabilir.

- Müteakip (Consecutive) XT: Tabanı içerde prizmalar daha çok tek başına veya en düşük hipermetropik ya da maksimum miyopik tashihle beraber kullanılır. Diplopi oluşursa cerrahi yapılmalıdır.

- Sensoryel şaşılık: Örneğin, uzun süreli katarakta sekonder XT varlığında, varsa diplopiyi düzeltmek için prizmalar kullanılabilir.

\section{B. İnkomitan şaşılıkta prizma tedavisi}

Burada temel gayeler, 1 . diplopiyi düzeltmek, 2. anormal baş pozisyonunu ( $A B P$ ) düzeltmek, 3. karşıya ve aşağı bakışta tek görme sağlamaktır.

Genel yaklaşım ilkeleri:

1. Temel amaçları sağlayan en az prizma diyoptrisi tespit edilmelidir.

2. Yetişkinler iyi gören göze Fresnel prizmasını kaldıramazlar.

3. Kombine kaymalarda oblik prizma kullanılır.

4. Muayene ortamında PAT denenmelidir.

5. Hekim Fresnel Prizmasını özellikle kendisi uygula- 
malı veya doğrulamalıdır.

6. Torsiyonel bakiye diplopi varsa hastanın prizmayı evde denemesi zamanla alışmasını sağlayabilir.

7. Hasta prizmalı gözlüğü önce güvenli bir çevrede denemelidir.

8. Binoküler görme alanı kaydı yararlı olur.

9. Gerekirse cam + Fresnel kombinasyonuyla 40 PD'e kadar verilebilir².

Konjenital inkomitan şaşılıklarda prizma pek kullanılmaz. Sonradan olma inkomitan şaşılıklarda, cerrahiye kadarki ilk 6-8 aylık bekleme süresi içinde veya cerrahiye yanaşmayan hastalarda -eğer Botulinum toksini uygulanmayacaksa-, diplopiyi ortadan kaldırmak için prizma kullanılabilir. Öncelikle hastanın karşıya bakış ve okuma pozisyonu olan aşağı bakıştaki (ya da kendisini en çok rahatsız eden pozisyondaki) diplopisinin giderilmeye çalışılacağı, bütün bakış yönlerinde bunun olası olmadığı kendisine izah edilmelidir.

Hem yatay hem de dikey diplopi durumunda, önce kayma ve diplopinin düzeldiği yatay ve dikey prizma değeri belirlenir. Tabanı yatay ve dikey arasındaki bölgede kalacak tek bir oblik prizma ayarlanır. Diyoptrisi yatay ve dikeyden fazla, ama toplamından az olmaIıdır. Sonra rotasyonla uygun eksen yakalanır. Hastalar Fresnel prizmasının paretik gözde olmasını tercih eder. Bir göz belirgin az görse bile diplopi rahatsız edebilir. İspatlanmamış olsa da, paretik göze prizma takılmasının kontraktür gelişimini önleyeceği öne sürülmüştür²

- Merkezi füzyon bozulmasına bağlı diplopi: Enderdir. Çoğunlukla komalı kapalı kafa travması sonrası ortaya çıkar. Prizma tedavisi çok yüz güldürücü değildir. İstekli hastada denenebilir ${ }^{14,15}$.

- Miyastenya gravis: Etkili tedaviye rağmen, miyastenili hastaların yarısına yakınında oküler semptomlar 14 yıla kadar devam edebilir. Bazı hastalarda, sabahları semptom yokken, günün ilerlemesiyle diplopi gelişebilir. Eğer sabit bir açı varsa tek bir prizmatik gözlük yeterli olabilir. Bunlarda birden fazla farklı prizmatik gözlük dahi verilebilir. Çene yukarda ABP için konjuge tabanı yukarda prizmalar yararlıdır ${ }^{16}$. Konverjans azlığı için tabanı içeride prizma verilir.

- Tiroid orbitopati: Cerrahiye kadar veya cerrahi sonrası sabit şaşılık ve diplopi için prizma kullanılır. Büyük açılı şaşılık (Örn. ET) cerrahiyle düzeltilip, kalan vertikal diplopi için prizma düşünülebilir. Bu hastaların füzyon kapasiteleri özellikle dikeyde anormal derecede geniştir. Bu nedenle gerekli prizma derecesi, objektif açıdan daha küçüktür. Hasta felçli gözle fiksasyonu tercih edebilir. Karşı bakış ve alt bakışta farklı derecede Fresnel (bifokal) prizmalar verilebilir. Alt rektusu fibrotik bir hastada bazen okurken diplopi olmadığı halde, karşıya bakışta diplopi olur. Bu durumda Fresnel prizması yalnızca orta kısım için kesilir, alta kon$\mathrm{maz}^{17}$.

- Diğer: Glokom drenaj cerrahisi ${ }^{18}$, orbita tümörleri, travma-orbita kırıkları ${ }^{19}$, sörklaj cerrahisi sonraSı şaşılık ve diplopi durumlar ${ }^{20}$, retrobulber veya peribulber anesteziye bağlı kas kontraktürü gibi durumlar ${ }^{21}$, artan yaşam süresi ile birlikte gittikçe daha sık olarak karşımıza çıkmaktadır. Prizmalar bu durumların hepsinde başarıyla kullanılabilir.

\section{Nistagmusta prizma tedavisi}

Nistagmusta öncelik refraktif düzeltmedir. Özellikle sferik değer yanında astigmatın tam düzeltilmesi önemlidir. Metzger 1950 yılında, nistagmuslu hastalardaki anormal baş pozisyonunun prizmalar kullanılarak düzeltilebileceğini ortaya koymuştur ${ }^{12}$. Bu amaçla, eğer hastada sağa veya sola yüz çevirme varsa konjuge yatay prizmalar, sağ veya sol omuza baş eğme varsa konjuge oblik prizmalar ve konverjansla nistagmus blokajı tedavisi için de tabanı dışarıda prizmalar kullanılmasını teklif etmiş̧iir ${ }^{22}$. Nistagmuslu hastalarda prizma kullanılması tayininde PAT çok yararlıdır. $\mathrm{PAT}$, hem $\mathrm{ABP}$ 'nin düzeltilip düzeltilemeyeceğinin tayinini sağlar hem de cerrahi miktarını belirler.

- Şaşılığın eşlik etmediği ABP'li nistagmus: Prizma tabanları $A B P$ yönüne doğru konur:

Örneğin, sağa yüz çevirme için, sağa tabanı dışarda, sola tabanı içerde prizma uygulanır. 
Örneğin, çene yukarıda ABP için, iki göze tabanı yukarda prizma tatbik edilir.

Örneğin, sağ omuza baş eğme varsa sağ göze tabanı dışarıda ve aşağıda sol göze tabanı içerde ve yukarda oblik prizmalar konur.

ABP prizmalarla düzelirse, ameliyat buna göre planlanabilir. Bu şekilde, yalnızca ABP'nin açı cetveliyle ölçüldüğü değerlere göre elde edilen sonuç temelinde yapılan cerrahiye göre daha başarılı sonuç elde edilebilir.

- Konverjansta Nistagmus Blokajı: Tabanı dışarıda en düşük prizma verilir. Uyarılan akomodasyon için miyopik cam ilave etmek de gerekebilir.

- $A B P$ ve şaşılıklı nistagmus: Öncelik ABP düzelmesini de hesaba katan bir şaşılık cerrahisinindir. Eğer

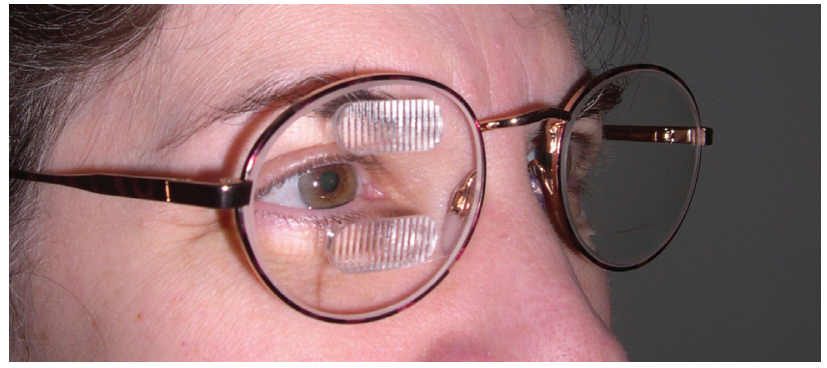

A

Resim 1a. Horiz 40 pprism: Hemianopi için yatay planda yerleştirilmiş 40 PD'lik kalıcı periferik Fresnel prizma segmentleri. b. Oblique 57 pprism: Hemianopi için oblik planda yerleştirilmiş 57 PD'lik kalıcı periferik Fresnel prizma segmentleri (Dr. Alex Bowers'in arşivinden kendi onayıyla alınmıştır).
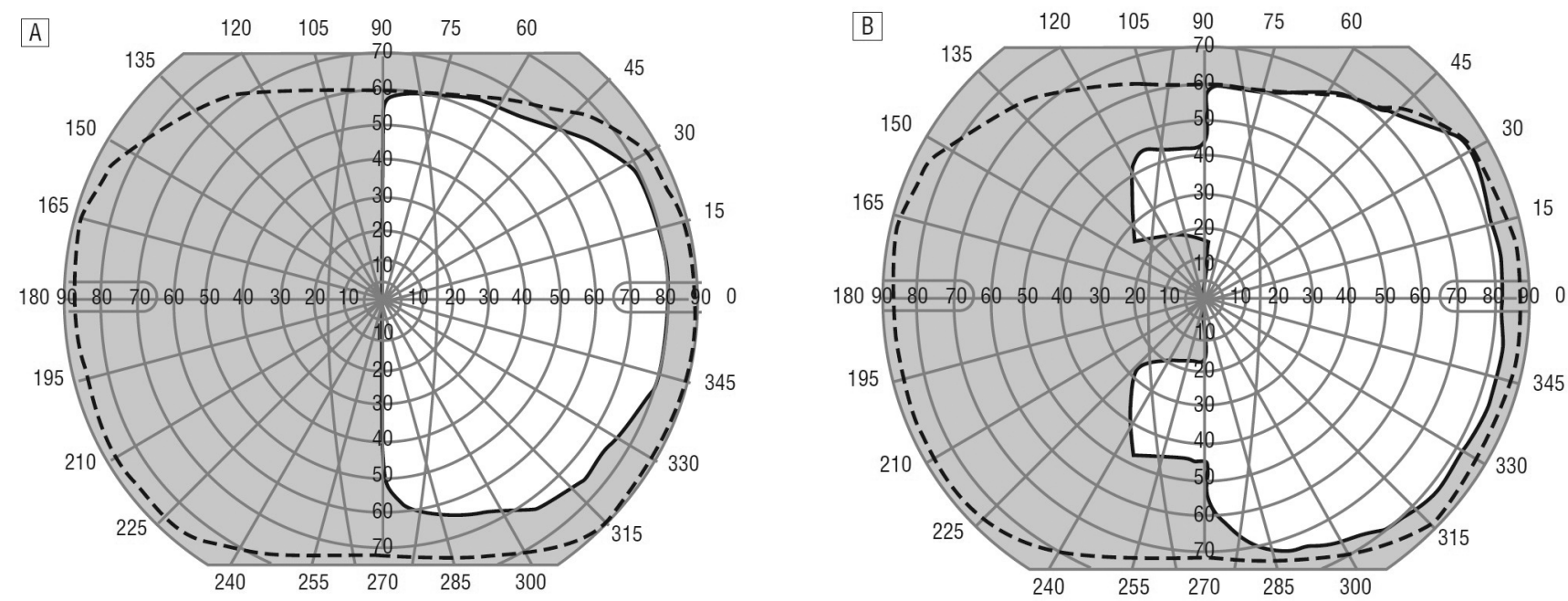

Resim 2a. Hemianopik bireyde görme alanı; b. Hemianopik bireyde Resim 1a'daki prizmalı gözlükle genişlemiş görme alanı (Dr. Eli Peli’nin arşivinden kendi onayıyla alınmıştır). 
- Maküla fonksiyon bozukluklarında da hastaların görsel performansını arttırmak için prizmalar kullanılabilmektedir ${ }^{26}$. Bu hastalar için prizmatik göz içi lensi de teorik bir alternatif olarak düşünülebilir.

- Bunun dışında, sınırlı hareket imkanı olan, postürü bozulmuş veya yatalak bireyler için, yakın ve uzak görüş için, açısı değiş̧irilebilen aynayla kombine edilmiş özel prizmalar kullanılabilir.

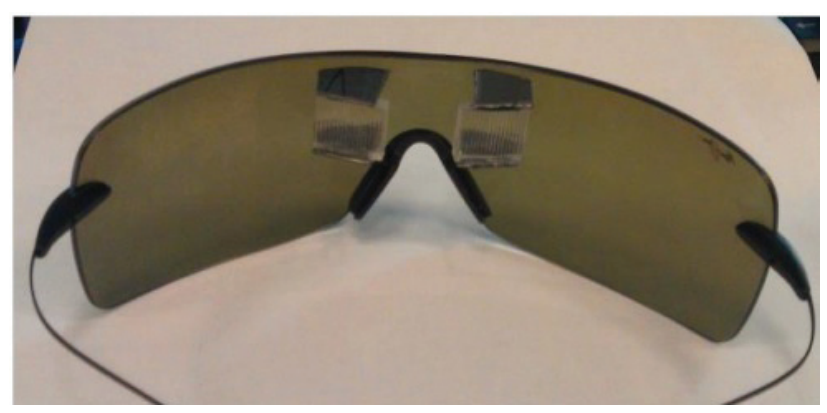

Resim 3. Bitemporal hemianopi için dizayn edilmiş, her iki nazal iç kısımda prizma içeren gözlük (Dr. Eli Peli'nin arşivinden kendi onayıyla alınmıştır).

\section{Prizma kullanılması önerilmeyen durumlar:}

- Erken başlangıçlı ET: Veronneau-Troutman 6-12 aylık infantil ezotropyalı bebeklerde cerrahiye kadar Fresnel prizma kullandığı çalışmasında, prizma kullanılmadan 6-24 ay arasında ameliyat edilen kontrol grubuyla sensoryel sonuçların aynı bulunduğunu bildirmiştir (11).

- Küçük açılı ET (Mikrotropya): Bu hastalarda 4-10 PD'lik bir kayma ile, çoğunlukla bir miktar füzyon amplitüdü, Worth 4 nokta ve Bagolini testlerinin müsbetliği ve azalmış stereopsis vardır. Ambliyopik gözün görme keskinliği, 0.2-0.9 (1.0) arası değişebilir. Bunlarda sensoryel anomali derin yerleşmiştir; tedavisi genelde başarısızdır. Prizma kullanılmamalıdır ${ }^{(2,4)}$.

- Anormal Retinal Korrespondanslı (ARK) ET: Az sayıda araştırmacı ARK tedavisinde prizma kullanımını savunmuşsa da ${ }^{27}, A R K^{\prime}$ nin prizma ile tedavisi sonuçları, diğer tüm tedaviler gibi ümit kırıcıdır2,4. Mikrotropya ve kaba stereopsis elde edilebilecek en iyi sonuçtur. Üstelik prizma vb. ortoptik tedavilerle kalıcı diplopi oluşturma riski vardır.

- Intermitant ET: Daha çok akomodatif ET'nin baş- langıcında görülür. Hipermetropik tashihe iyi cevap verir. Akomodatif olmayan ET'de de görülebilir. Tetiği çeken neden her zaman bulunamaz. Intermitant XT'nin tersine, intermitant ET manifest olduğunda hasta bulanık veya çift görür. Binokülarite iyidir. Prizma tedavisi için uygun değillerdir. Cerrahiyle gözler paralel hâle gelirse binokülarite toparlanır².

- Ambliyopi tedavisinde prizmaların etkinliği gösterilmiş değildir. von Noorden bu amaçla prizma kullanımını önermemektedir ${ }^{4}$.

- Yetişkin monoküler ambliyoplar, sağlam göze kapama yaparlarsa, diplopi gelişebilir. Böyle hastalarda prizma kullanılmamalı, kapama sonlandırılmalıdır.

\section{KAYNAKLAR}

1. American Academy of Ophthalmology: Optics and refraction and contact lenses; Basic and Clinical Science Course. San Fransisco, AAO; 1989-1990:54-58.

2. Veronneau-Troutman S. Prisms in the medical and surgical treatment of strabismus. St Louis; Mosby Co 1994: 95-176.

3. Ansons AM, Davis H. Diagnosis and management of ocular motility disorders. London; Blackwell Ssience. 2001: Section II (8): 145-147.

4. von Noorden GK, Campos EC. Binocular vision and ocular motility: Theory and management of strabismus. 6. Editions, St Louis; Mosby Co. 2002; 16: 314, 445, 540, 550.

5. Lie I, Opheim A. Long-term stability of prism correction of hetrophorics and heterotropics: a 5 year follow-up. J Am Optom Assoc 1990; 61: 491-498.

6. Worrell BE Jr, Hirsch MJ, Morgan MW. An evaluation of prism applied by Shierd's Criterion. Am J Optom Arch Am Acad Optom 1971; 48: 373-376. http://dx.doi.org/10.1097/00006324-197105000-00001

7. Rubin W. Reverse prism in ocular motility problems. In: Ferrer O, ed; Ocular motility: Int Ophthalmol Clin. Vol: 11(4); Boston; 1971; Little, Brown and Co., 263-268, 292-295.

8. Bixenman WW, Langanu JF. Acquired esotropia as initial manifestation of Arnold-Chiari malformation. J Pediatr Ophthalmol Strab 1987; 24: 83-86.

9. Worrell BE Jr, Hirsch MJ, Morgan MW. Acute comitamt esotropia in children with brain tumors. Arch Ophthalmol 1989; 107: 376-378.

http://dx.doi.org/10.1001/archopht.1989.01070010386029

10. Hardesty HH. Treatment of under and overcorrected intermittent exotropia with prism glasses. Am Orthopt J 1969; 19: 110-119.

11. Veronneau-Troutman S. Fresnel prisms in the treatment of strabismus. Can J Ophth 1971; 6: 249-257.

12. Edelman PM, Brown MH, Murphree AL et al. Consecutive esodeviation... Then what? Am Orthop J 1988; 38: 111-116.

13. Caltrider $\mathrm{N}$, Jampolsky A. Overcorrecting minus lens therapy for treatment of intermittent exotropia. Ophthalmology 1983; 90: 1160-1165. http://dx.doi.org/10.1016/S0161-6420(83)34412-2 
14. London R, Scott S. Sensory fusion disruption syndrome. J Am Optom Assoc 1987; 58: 544-546.

15. Pratt-Johnson JA, Tillson G. The loss of fusion in adults with intractable diplopia (central fusion disruption). Aust New Zeal Ophthalmol 1988; 16: 81-85. http://dx.doi.org/10.1111/j.1442-9071.1988.tb01254.x

16. Diamond S. Prism management of vertical incomitance; Case reports; Conjugate prism correction for ocular myastenia. $\mathrm{Tr}$ Pac Coast Oto-Ophthalmol Soc 1965; 46: 135.

17. Lueder GT, Scott WE, Kutsche PJ et al. Lon-term results of adjustable suture surgery for strabismus secondary to thyroid ophthalmopathy. Ophthalmology 1992; 99: 993-1093. http://dx.doi.org/10.1016/S0161-6420(92)31866-4

18. Munoz M, Parrish R. Hypertropia after implantation of a Molteno drainage device. Am J Ophthalmol 1992; 113: 98-100. http://dx.doi.org/10.1016/S0002-9394(14)75762-9

19. Lyon DB, Newman SA. Evidence of direct damage to extraocular muscles as a cause of diplopia following orbital trauma. Ophthal Plast Reconstr Surg 1989; 5: 81-91. http://dx.doi.org/10.1097/00002341-198906000-00002

20. Fison PN, Chignell AH. Diplopia after retinal detachment surgery. Br J Ophthalmol 1987; 71: 521-525. http://dx.doi.org/10.1136/bjo.71.7.521
21. Hamed LM, Mancuso A. Inferior rectus muscle contracture syndrome after retrobulbar anesthesia. Ophthalmology 1991; 98: 1506-1512. http://dx.doi.org/10.1016/S0161-6420(91)32097-9

22. Metzger EL. Correction of congenital nystagmus. Am J Ophthalmol 1950; 33: 1796-1797.

23. Perlin RR, Dziadul J. Fresnel prisms for field enhancement in patients with constricted or hemianopic visual fields. J Am Optom Assoc 1991; 62: 58-64.

24. Bowers AR Tant M, Peli E. A pilot evaluation of on-road detection performance by drivers with hemianopia using oblique peripheral prisms. Stroke Res Treat 2012; 2012: 176-806.

25. Bowers AR, Keeney K, Peli E. Randomized crossover clinical trial of real and sham peripheral prism glasses for hemianopia. JAMA Ophthalmol 2014; 132: 214-22. http://dx.doi.org/10.1001/jamaophthalmol.2013.5636

26. Rosenberg $\mathrm{R}$, Faye $\mathrm{E}$, Fischer $\mathrm{M}$ et al. Role of prism relocation in improving visual performance of patients with macular dysfunction. Optom Vis Sci 1989; 66: 747-750. http://dx.doi.org/10.1097/00006324-198911000-00004

27. Pigassou-Albouy R. Prism therapy for strabismus. J Ophthal Nurs Technol 1988; 7: 18-25. 